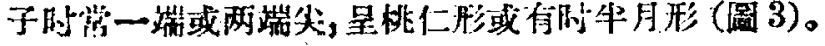

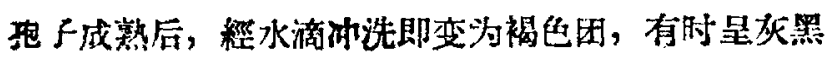

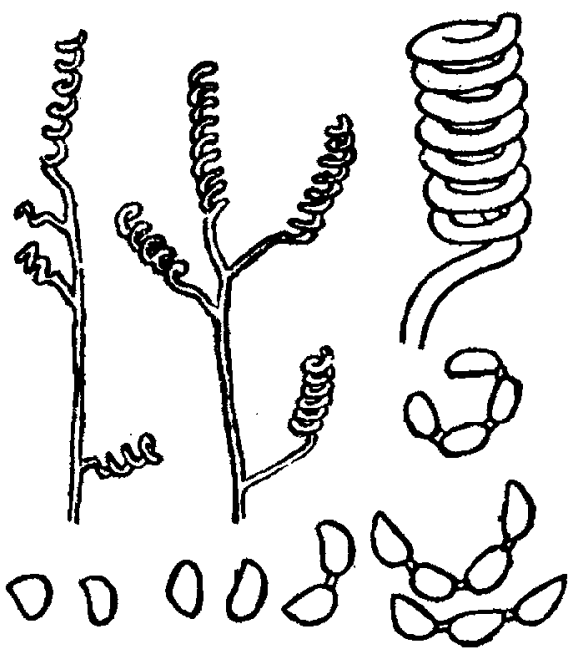

四 3 Ail. atrolaccus

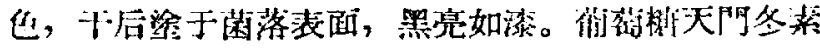

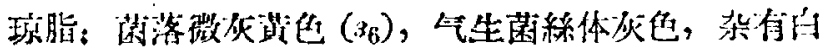

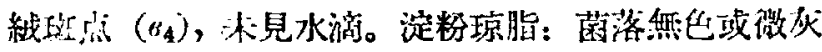

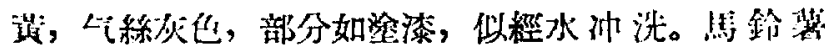

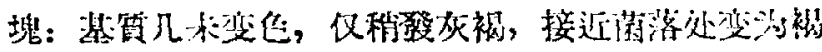

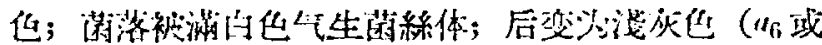

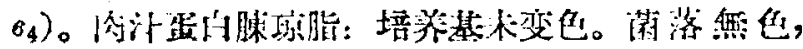

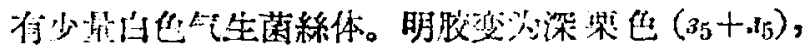

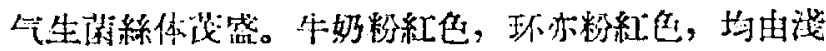

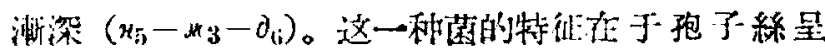

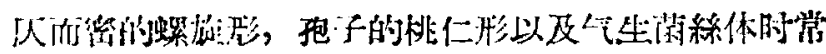

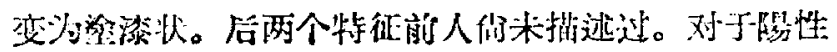

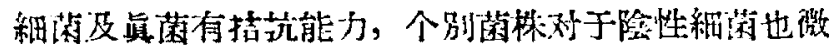
有强制作用。生理特性兒上表。

$$
\text { 閻 逊 初 }
$$

(中国科学院菌种保藏委呈会) 1957 年。月21日

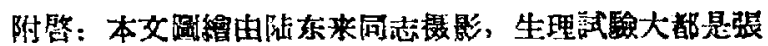
国傽同志所作, 諽此志謝。

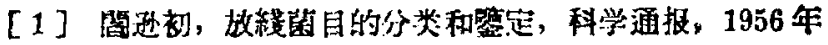
第 1 期。

[2] A.C. Бондарціо, Шкала ціветов,

\section{黑龙江水系地質及工程 地留的初步覌察}

1956 年 7 月至 9 月，作省参加了中国科量院完和苏

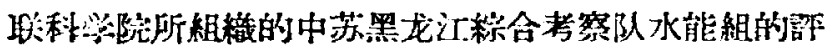

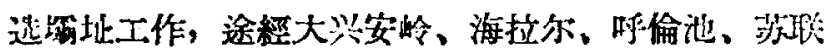

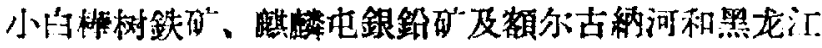

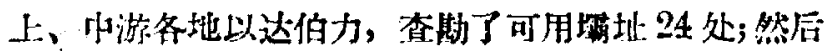

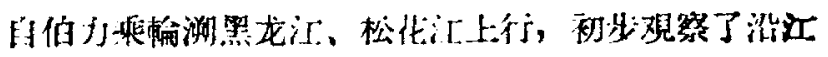
湿地（沿罢地）及三姓淺濑，回到合尔演总紹。

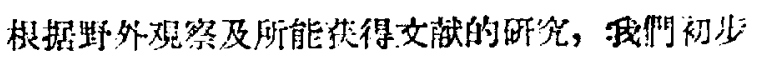

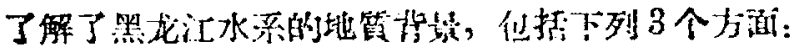

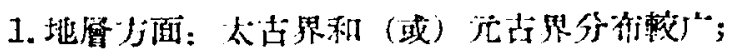

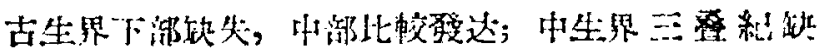

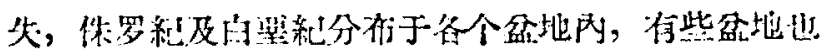

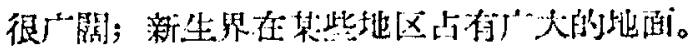

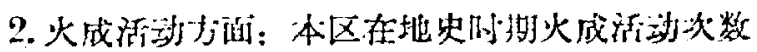

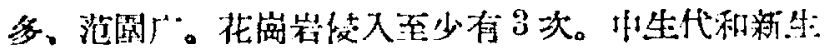
代的火活新也比較此繁，而且影响很大。

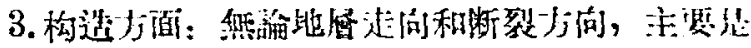

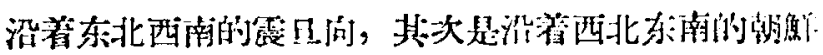

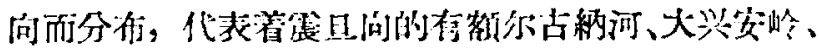

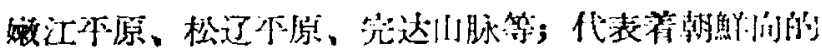

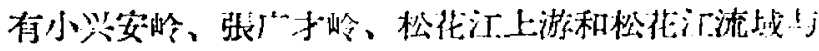

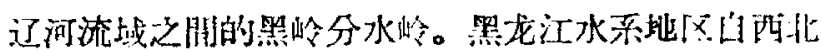

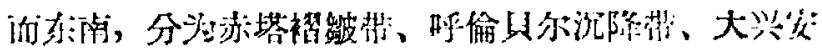

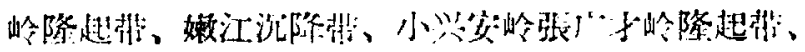

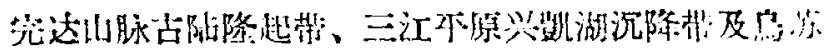

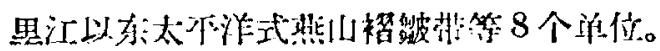

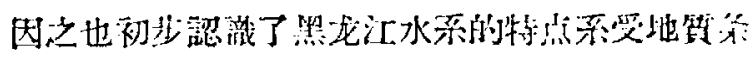

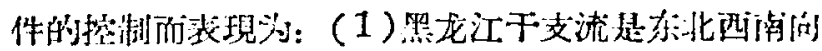

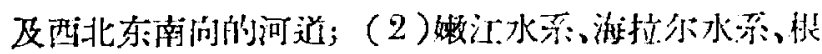

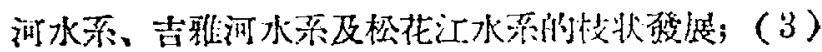

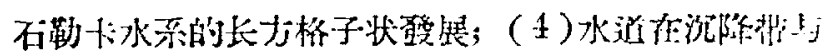

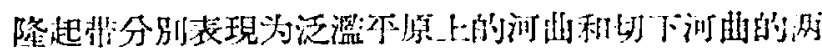

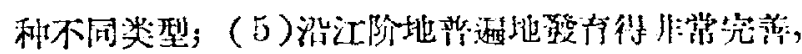

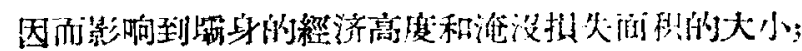

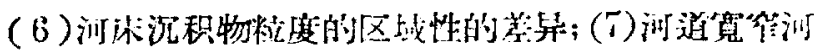

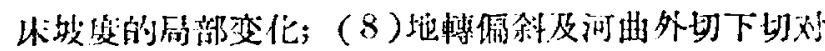

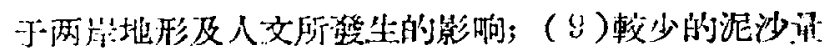

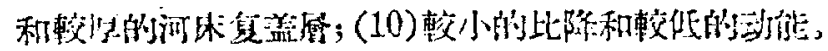

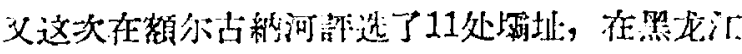

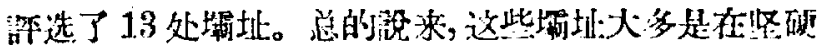

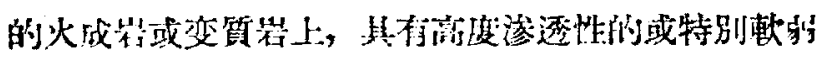

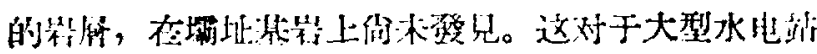
的建设琶有利的。

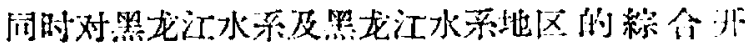

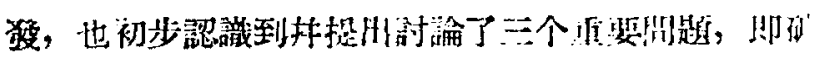

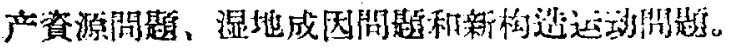

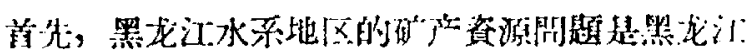

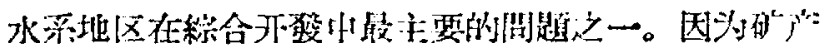

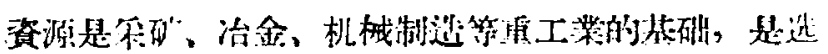

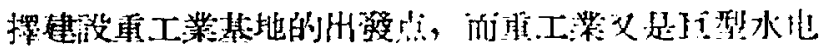

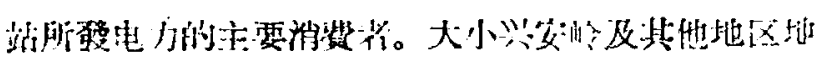




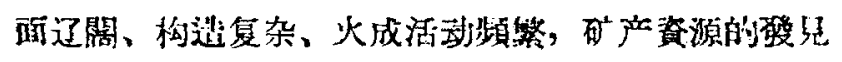
煶很有希望的，应加紧調查研究。

其次，黑龙江水景地区的湿地問题非常亜重。以

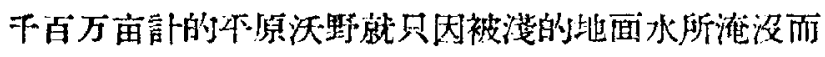

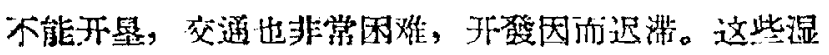
地的产状或是現代泛濫巫原上的曲流，或当河流的会 中，或在河流入游、入湖的河口，或为古牛顿湖汀低，

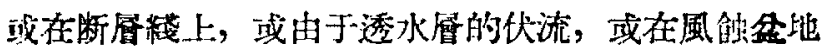

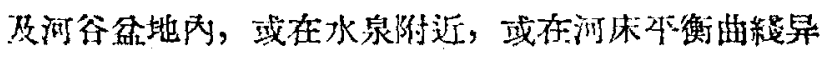

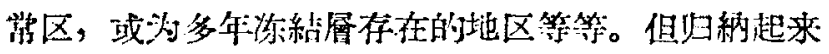
湿地形成的基本覞律不外是由于: (1)地形的原因(風

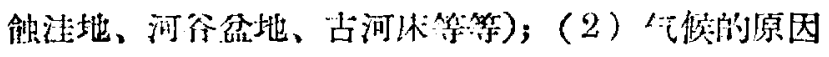
(降雨量多、冰冻胡地、蒸登量小、解拣翻浆等算);

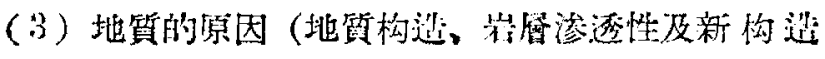

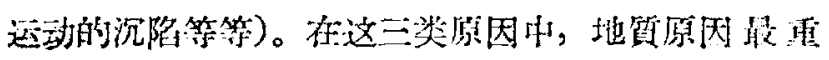

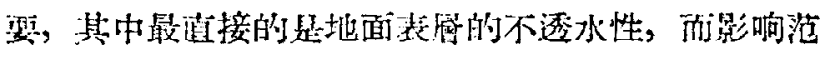

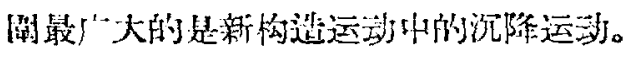

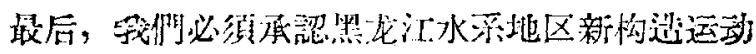

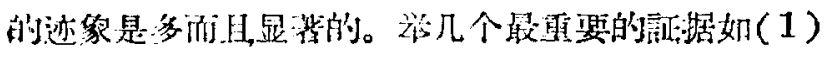
三妙（依兰）湝瀨的形成，(2)黑龙江和松花江及其

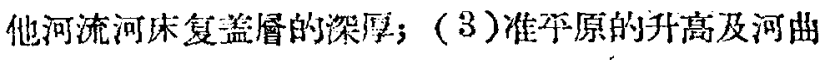
和切下河曲的形成; (4)新火山現象的普遍; (5)局

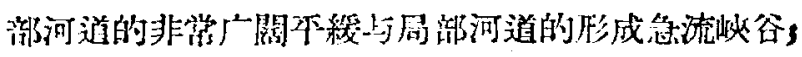

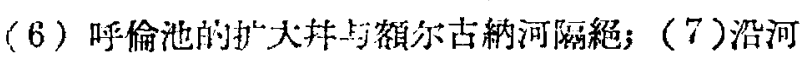

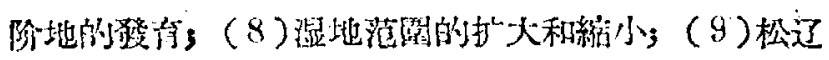

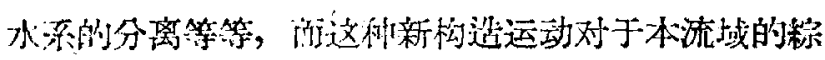
合仃䘣是有影响的。

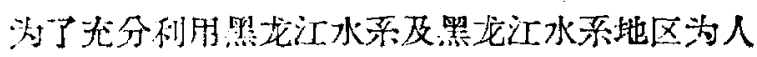

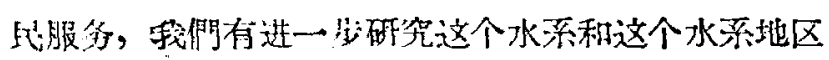

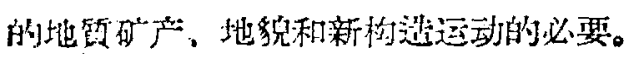

$$
\begin{gathered}
\text { 馮景 兰 } \\
\text { (北京地留学院) } \\
\text { 1957年 } 2 \text { 月 } 22 \text { 日 }
\end{gathered}
$$

\section{华北平原第四紀沉积物的 性質及其演变}

华北吏原第四䄫沉积物的种类很多，有洪积物、冲 和物、湖积物、風积物及海积物。由于䒚河及其他河流 的泛濫和改道, 第四紀河流沉积物的分布更趋复染。

洪积物及洪积计积物多分布于山上楚阶地或冲积

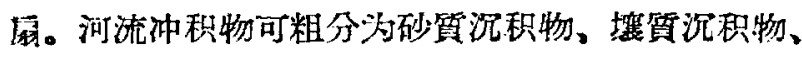
粘質沉积物及头胶泥壤質沉积物 4 和喽型，再按質地

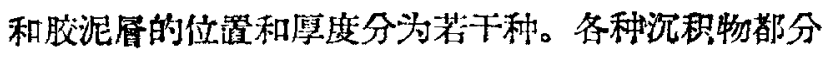
布在一定地形部位上。湖泊地区和老沼羄地有湖积

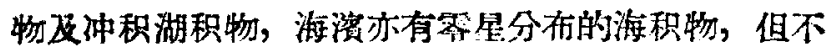

太多，海边底部埋藏有海积物。洪积物、冲积物及游 滩物質，可因風力搬运而成風积物。

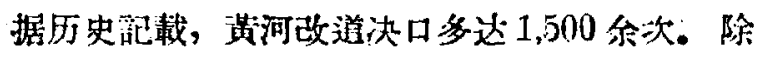

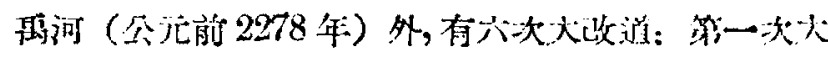

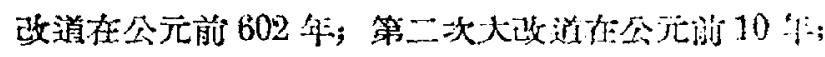
第一次及第二次大改道之闍的决口为策汉故通；符：： 次大改通在公元 1038 年; 第四次大改道作尽元 $11 \times 4$

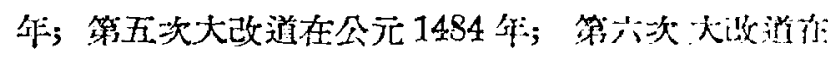
公元 1855 年。

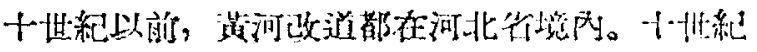

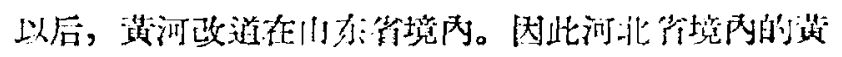

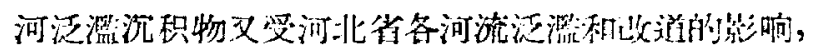
其中以济河及濾论河的影响最大。

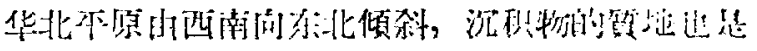

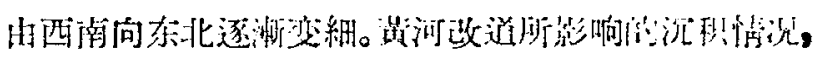

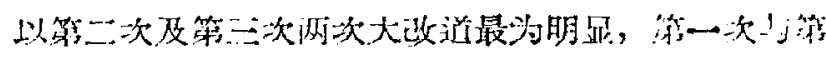

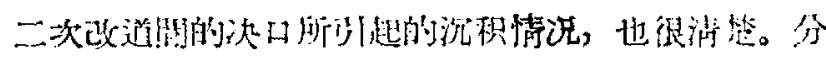

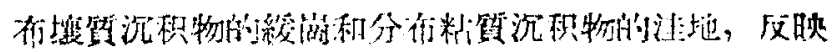

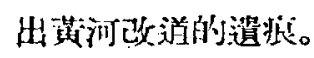

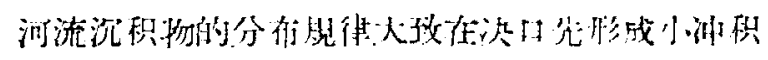

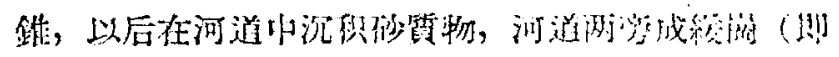

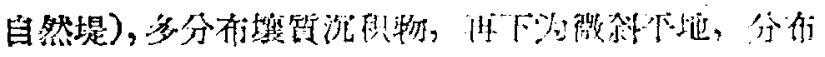

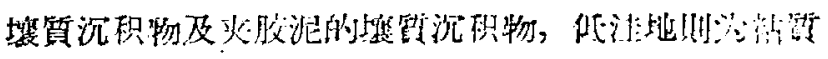
沉积物。但他河流改通、决口和泛濫次数太多，测流

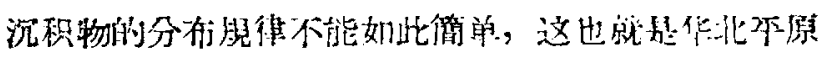
中河流沉段讪特热。

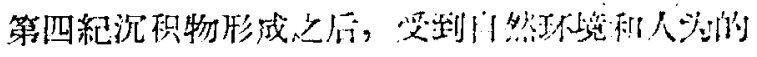

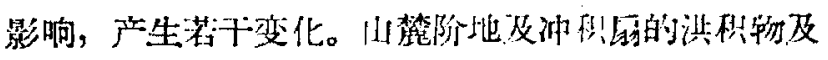

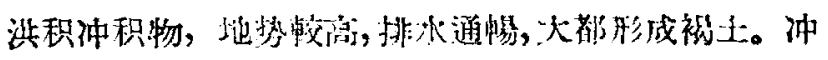

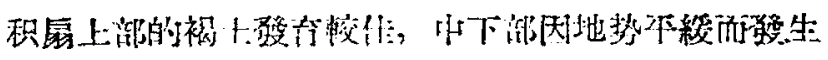

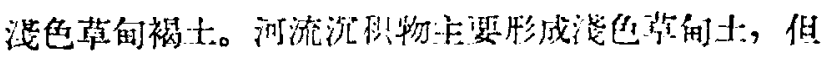

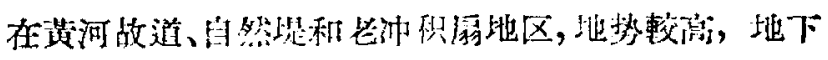

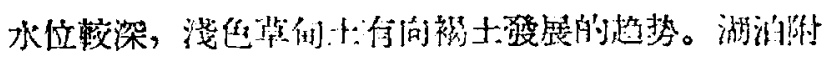

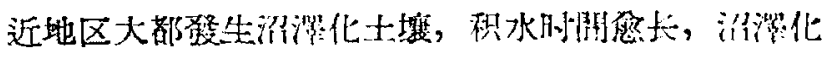

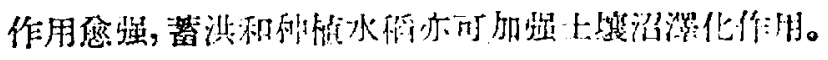

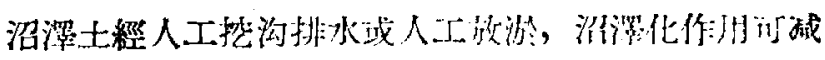

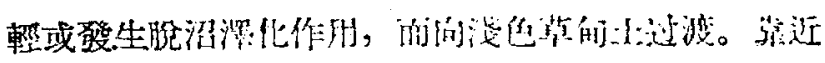

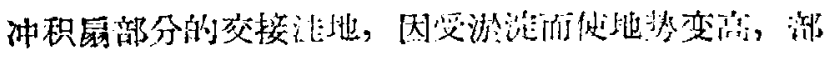

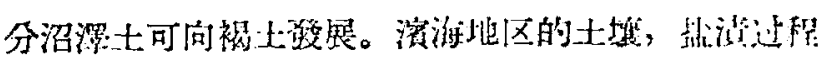

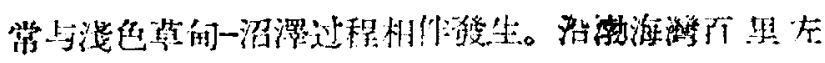

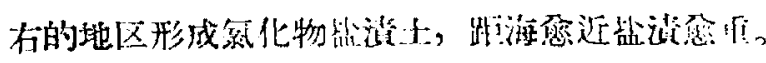

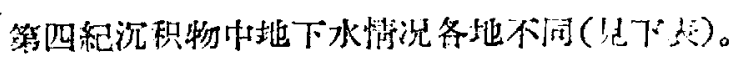

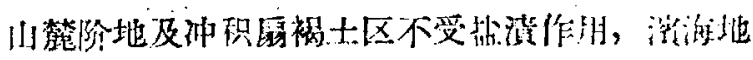

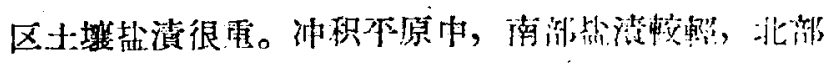
多攻状盐清土分斩。

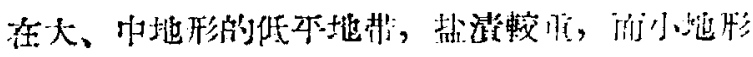

